\title{
SISTEM KONTROL AR.DRONE 2.0 DENGAN WIFI BERBASIS LABVIEW Marfin $^{1}$, Djoko Hari Nugroho ${ }^{2}$
}

\author{
${ }^{1}$ Dosen Jurusan Teknik Elektro FT UNPAM \\ ${ }^{2}$ Institut Sains dan Teknologi Nasional \\ Jln. Puspiptek Raya No 11 Buaran, Tangerang Selatan 15310 INDONESIA \\ Iarsyafin@gmail.com \\ ${ }^{2}$ djokohn@yahoo.com
}

\begin{abstract}
ABSTRAK
Ada dua pilihan utama untuk mengembangkan quadrotor yang cocok untuk penelitian yaitu membeli model dari pabrikan (tidak memiliki interface dengan komputer) atau membangun quadrotor dari awal (proses pengembangan teknologi, waktu yang panjang dan sulit serta perlu biaya yang tidak sedikit). Drone sudah banyak dipergunakan, salah satu penggunaannya adalah untuk pemantauan kepadatan lalu lintas. Penelitian ini bertujuan untuk merancang dan membangun piranti lunak yang berjalan pada komputer sebagai sarana untuk membangun link ke AR.Drone 2.0 untuk keperluan komunikasi dan kontrol. Dengan pengembangan sistem kontrol AR.Drone 2.0 dengan WiFi berbasis LabVIEW diharapkan akan dapat dilakukan inovasi lebih lanjut misalnya untuk memantau kepadatan lalu lintas. Metodologi yang dilakukan adalah melakukan analisis, perancangan dan pengujian sistem. Berdasarkan hasil eksperimen tampak bahwa sistem kontrol AR.Drone 2.0 menggunakan program LabVIEW dengan bantuan joystick bisa melakukan gerak pitch, roll, yaw, climb, hover dan dapat ditampilkan dengan baik pada user interface.
\end{abstract}

Kata kunci : sistem kontrol, drone, LabVIEW, wifi

\begin{abstract}
AR.DRONE 2.0 CONTROL SYSTEM WITH WIFI BASED ON LABVIEW. There are two main options for developing a compatible quadrotor for research that is buy a model from manufacturer (no have inteface with computer) or build quadrotor from the beginning (technology development process, a long time, difficult and need cost not a little). Drones are many used, one of use is for traffic monitoring. This research intend for planning and build software running on the computer as medium for build link to AR.Drone 2.0 for need communication and control .Development of AR.Drone 2.0 control systems with WiFi based on LabVIEW is expected to do further innovation for example in traffic monitoring. The methodology utilized in this research are performance analysis, design and testing system. Experimental results shows that the control system AR.Drone 2.0 uses LabVIEW programs completed with joystick can perform motion pitch, roll, yaw, climb, hover and can be displayed well on the user interface.
\end{abstract}

Keywords : control systems, drones, LabVIEW, wifi.

\section{PENDAHULUAN}

A da dua pilihan utama untuk mengembangkan quadrotor yang cocok untuk tujuan penelitian yaitu membeli model dari pabrikan atau membangun quadrotor dari awal. Tak ada satu pun pilihan tersebut yang sangat ideal. Sebuah quadrotor profesional seperti Draganfly X4 biayanya lebih dari $\$$ 12.000 ( \pm 156 jutaan), dan kekurangan lain pada remot kontrolnya seharga beberapa ratus dolar dan tidak memiliki interface dengan komputer, tidak memiliki sensor canggih. Namun untuk membangun 
quadrotor dari awal perlu proses pengembangan teknologi, waktu yang panjang dan sulit serta perlu biaya yang tidak sedikit [1].

Untuk membangun quadrotor diperlukan pengetahuan teknis tentang desain sirkuit, pemrograman, fabrikasinya, dan pengalaman menggunakan remot kontrol. Setelah mendapatkan sumber informasi dan quadrotor telah dibuat, kontrol algoritma harus dikembangkan dan diimplementasikan pada quadrotor. Kontrol algoritmanya harus benar-benar diatur untuk memastikan stabilitas quadrotor. Bahkan harus melakukan simulasi terus-menerus dalam pengujian penerbangan dan selalu ada crash dalam pengujian tersebut. Banyak developer yang membangun dan mengembangkan quadrotor meskipun mengalami proses trial and error.

Pada tahun 2010, perusahaan Perancis yang biasa membuat komponen ponsel yaitu, Parrot, menciptakan quadrotor yang disebut AR.Drone 2.0 dan ditunjukkan pada Gambar 1.1 seharga $\$ 300$ ( \pm 4 jutaan). Drone ini memiliki fitur yang dapat terhubung ke komputer dengan WiFi, dan dapat dilengkapi dengan sejumlah sensor seperti akselerometer, giroskop, altimeter ultrasonik, dan dua kamera video, satu menghadap ke depan dan satu menghadap ke bawah. Dari latar belakang itulah, AR.Drone 2.0 dipilih untuk penelitian. Karena AR.Drone 2.0 dirancang sebagai permainan, aeromodeling, dan augmented reality, maka satu-satunya cara yang didukung secara resmi untuk bisa terbang adalah dengan menggunakan aplikasi smartphone gratis pada iPhone atau Android [2].

Untuk pengembangan sistem autonomous yang memerlukan konsep canggih dalam kecerdasan buatan maupun sistem koordinasi, memerlukan antarmuka yang dapat dikendalikan dari computer PC/laptop dengan asumsi bahwa perangkat komputasi paling efektif saat ini untuk pengembangan konsep komputasi dan HMI (Human Machine Interaction) adalah komputer PC atau laptop. Dengan demikian sebuah link ke komputer diperlukan agar pengguna dapat menulis kode untuk mengontrol AR.Drone 2.0 dan memonitor saat terbang. Jika ada cara untuk menghubungkan AR.Drone 2.0 ke komputer, pengguna bisa membaca sensor dan video streaming secara live, perintah dan melakukan manuver pada AR.Drone 2.0, dan menerapkan kontrol algoritma loop tertutup antara input sensor dan kontrol output untuk membuat sistem otonom yang canggih. Penelitian ini bertujuan untuk merancang dan membangun piranti lunak yang berjalan pada komputer sebagai sarana untuk membangun link ke AR.Drone 2.0 untuk keperluan komunikasi dan kontrol.

\section{TEORI \\ Drone}

Drone adalah pesawat tanpa awak (Unmanned Aerival Vehicle/UAV) yaitu mesin terbang yang dikendalikan dari jarak jauh oleh pilot atau dapat mengendalikan dirinya sendiri, dengan memakai hukum aerodinamika, dapat digunakan kembali dan mampu mengangkut muatan. Benda terbang ini mempunyai bentuk, ukuran, konfigurasi dan karakter yang berbeda-beda [3]. Kontrol terhadap drone ada dua macam yaitu:

1. Dikontrol melalui pengendali jarak jauh.

2. Terbang secara mandiri berdasarkan program yang ditanam dalam tubuh pesawat lain.

\section{LabVIEW}

LabVIEW (singkatan dari Laboratory Virtual Instrumentation Engineering Workbench) adalah perangkat lunak komputer untuk pemrosesan dan visualisasi data dalam bidang akuisisi data, kendali instrumentasi serta automasi industri yang pertama kali dikembangkan oleh perusahaan National Instruments pada tahun 1986 [5].

\section{WiFi}

WiFi adalah kependekan dari Wireless Fidelity. WiFi dapat diartikan sebagai sekumpulan standar yang digunakan untuk sebuah jaringan lokal nirkabel atau sering disebut dengan Wireless Local Area Networks (WLAN) yang didasari pada spesifikasi IEEE 802.11.

\section{METODOLOGI \\ Bahan dan Alat}

Bahan-bahan rujukan penelitian dapat diperoleh melalui diskusi dengan dosen pembimbing, serta melakukan percobaan di dalam atau di luar ruangan. Percobaan di 
dalam atau di luar ruangan bertujuan untuk memperoleh data-data yang diperlukan dalam analisis kebutuhan, perancangan dan implementasinya. Perangkat atau peralatan yang dibutuhkan dalam penelitian ini antara lain:

1. AR.Drone 2.0

2. Joystick

3. Komputer atau laptop dengan spesifikasi minimum Processor Intel Pentium 4, memory 1GB, Harddisk $10 \mathrm{~GB}$.

\section{Tata Kerja}

Metode yang digunakan dalam menyelesaikan penelitian ini adalah meliputi 4 bagian pokok sebagai berikut:

1. Pertama adalah metode analisis. Dalam penelitian ini, dilakukan beberapa cara untuk melakukan analisis; yakni dengan membaca literatur, buku, dan artikel yang berkaitan dengan AR.Drone 2.0 serta teori- teori lain yang terkait.

2. Kedua adalah metode perancangan. Dari hasil analisis dan studi pustaka yang diperoleh, dibuat sebuah rancangan sistem kontrol AR.Drone 2.0 dengan $\mathrm{WiFi}$ berbasis LabVIEW.

3. Ketiga adalah metode pengujian. Pengujian dilakukan terhadap kinerja AR.Drone 2.0, sejauh mana program dapat mengontrol drone tersebut dengan Joystick. Pengujian dilakukan di dalam dan di luar ruangan.

4. Keempat adalah hasil pengujian yang diperoleh dianalisis lebih lanjut dan dibandingkan dengan kontrol lain, untuk ditarik kesimpulan mengenai kinerja sistem. Juga dilakukan pengujian untuk menggerakkan AR.Drone 2.0 dengan tepat.

\section{Bagan Alir Sistem Kontrol}

Bagan Alir Sistem Kontrol AR.Drone 2.0 dengan LabVIEW dapat dilihat pada Gambar 1.

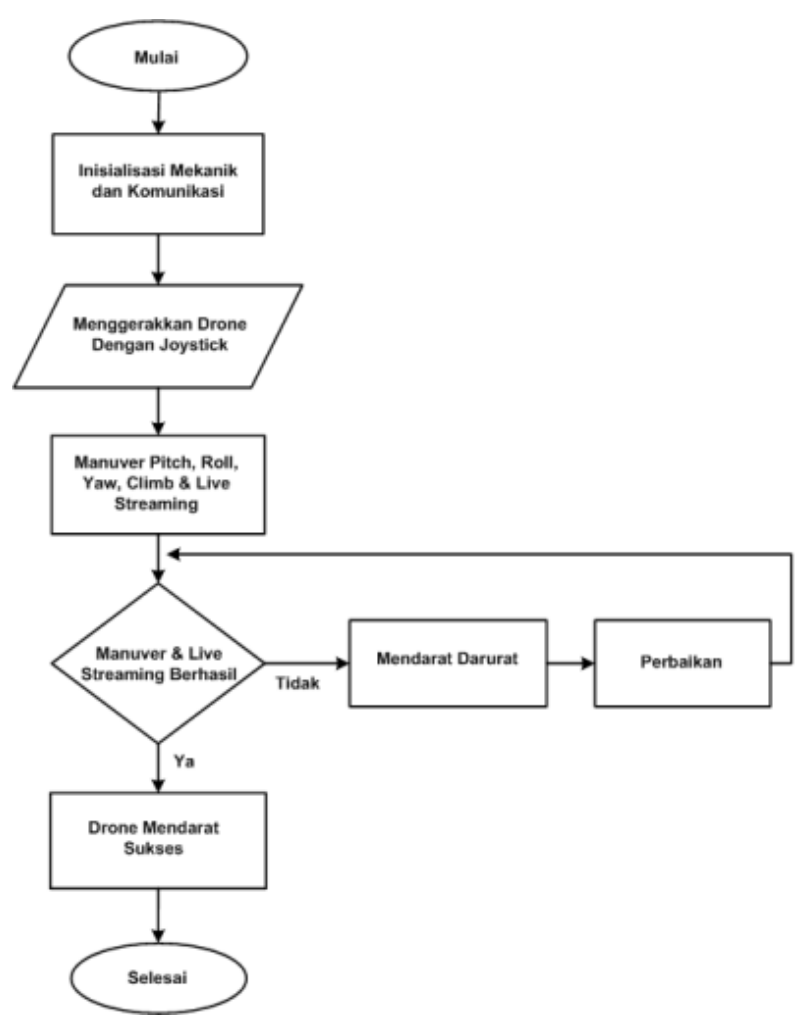

Gambar 1. Bagan Alir Sistem Kontrol AR.Drone 2.0 dengan LabVIEW

Pada gambar 1 dapat dilihat proses kerja sebagai berikut :

1. Inisialisasi AR.Drone 2.0 dengan Joystick. Menyalakan WiFi AR.Drone 2.0 dan WiFI pada Laptop untuk menghubungkan komunikasi antara AR.Drone 2.0 dengan Laptop yang di dalamnya terdapat program LabVIEW. Dan melakukan pengaturan Joystick untuk mengontrol AR.Drone 2.0.

2. AR.Drone 2.0 Lepas Landas dengan menekan tombol dari Joystick yang sudah di atur.

3. AR.Drone 2.0 melakukan gerakan Roll, Pitch, Yaw, Climb dan Live Streaming.

4. AR.Drone 2.0 mendarat ke permukaan dengan menekan tombol dari Joystick yang sudah di atur.

5. Jika mengalami error, tekan tombol pada joystick untuk mendarat darurat. 


\section{HASIL DAN PEMBAHASAN \\ Pengujian kontrol AR.Drone 2.0 dengan WiFi berbasis LabVIEW}

Pengujian HMI (Human Machine Interface) dilakukan dengan menguji setiap tombol yang ada pada sistem kontrol user interface yang dibuat dengan menggunakan pemrograman LabVIEW [4] seperti tampak pada Gambar 4.1 di bawah. Pengujian menunjukkan tombol-tombol dapat aktif merespons masukan dengan baik.

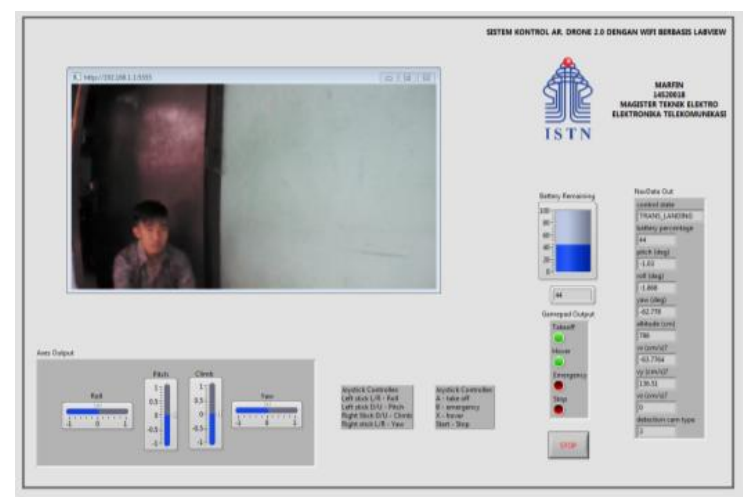

Gambar 2. Human Machine Interface sistem kontrol pada program LabVIEW

Tabel 1. Hasil Pengujian AR Drone 2.0

\begin{tabular}{|c|l|c|c|}
\hline No & Kapabilitas & $\begin{array}{c}\text { Perenca } \\
\text { naan }\end{array}$ & Hasil \\
\hline 1 & $\begin{array}{l}\text { Pengontrola } \\
\text { n oleh } \\
\text { LabVIEW }\end{array}$ & $\begin{array}{l}\text { Bisa } \\
\text { udara } \\
\text { dengan } \\
\text { stabil }\end{array}$ & Bisa \\
\hline 3 & $\begin{array}{l}\text { Melayang di } \\
\text { pitch, roll, } \\
\text { yaw dan } \\
\text { climb Bisa }\end{array}$ & Bisa \\
\hline
\end{tabular}

\begin{tabular}{|l|l|l|l|}
\hline 4 & Melakukan & & \\
& $\begin{array}{l}\text { Live } \\
\text { Streaming }\end{array}$ & Bisa & Bisa \\
\hline
\end{tabular}

Tabel 2. Bagian Detail Human Machine Interface Sistem Kontrol pada Program LabVIEW

\begin{tabular}{|c|c|c|c|}
\hline No & $\begin{array}{c}\text { Bagia } \\
\text { n } \\
\text { HMI }\end{array}$ & Hasil & $\begin{array}{c}\text { Ketera } \\
\text { ngan }\end{array}$ \\
\hline 1 & $\begin{array}{l}\text { Live } \\
\text { Strea } \\
\text { ming }\end{array}$ & & $\begin{array}{c}\text { Aliran } \\
\text { video } \\
\text { dikirim } \\
\text { oleh } \\
\text { AR.Dr } \\
\text { one } 2.0 \\
\text { pada } \\
\text { port } \\
5555\end{array}$ \\
\hline
\end{tabular}




\begin{tabular}{|c|c|c|c|}
\hline 2 & $\begin{array}{l}\text { NavD } \\
\text { ata }\end{array}$ & $\begin{array}{l}\text { NavData Out } \\
\text { control state } \\
\text { TRANS_LANDING } \\
\text { battery percentage } \\
44 \\
\text { pitch (deg) } \\
-1.03 \\
\text { roll (deg) } \\
-1.868 \\
\text { yaw (deg) } \\
-62.778 \\
\text { altitude }(\mathrm{cm}) \\
786 \\
\text { vx }(\mathrm{cm} / \mathrm{s}) ? \\
-63.7764 \\
\text { vy }(\mathrm{cm} / \mathrm{s}) ? \\
136.51 \\
\mathrm{vz}(\mathrm{cm} / \mathrm{s}) ? \\
0 \\
\text { detection cam type } \\
3 \\
\end{array}$ & $\begin{array}{c}\text { Inform } \\
\text { asi } \\
\text { tentang } \\
\text { drone } \\
\text { (seperti } \\
\text { status, } \\
\text { posisi, } \\
\text { kecepa } \\
\text { tan, } \\
\text { kecepa } \\
\text { tan } \\
\text { putaran } \\
\text { mesin, } \\
\text { dll) }\end{array}$ \\
\hline 3 & $\begin{array}{l}\text { Indika } \\
\text { tor } \\
\text { Batera } \\
\mathrm{i}\end{array}$ & Battery Remaining & $\begin{array}{c}\text { Tampil } \\
\text { an } \\
\text { keadaa } \\
\mathrm{n} \\
\text { baterai } \\
\text { secara } \\
\text { Realti } \\
\text { me }\end{array}$ \\
\hline 4 & $\begin{array}{l}\text { Axes } \\
\text { Outpu } \\
\mathrm{t}\end{array}$ &  & $\begin{array}{c}\text { Tampil } \\
\text { an arah } \\
\text { gerak } \\
\text { Drone } \\
\text { seperti } \\
\text { Roll, } \\
\text { Pitch, } \\
\text { Climb } \\
\text { dan }\end{array}$ \\
\hline
\end{tabular}

\begin{tabular}{|c|c|c|c|}
\hline & & & $\begin{array}{c}\text { Yaw } \\
\text { yang } \\
\text { digerak } \\
\text { kan } \\
\text { oleh } \\
\text { Joystic } \\
\text { k }\end{array}$ \\
\hline 5 & $\begin{array}{l}\text { Game } \\
\text { pad } \\
\text { Outpu } \\
\text { t }\end{array}$ & $\begin{array}{l}\text { Gamepad Output } \\
\text { Takeoff } \\
\text { Hover } \\
\text { Emergency } \\
\text { Stop } \\
\text { STOP }\end{array}$ & $\begin{array}{c}\text { Tampil } \\
\text { an } \\
\text { perinta } \\
\text { h } \\
\text { kepada } \\
\text { Drone } \\
\text { untuk } \\
\text { melaku } \\
\text { kan } \\
\text { Take } \\
\text { off, } \\
\text { Hover } \\
\text { dan } \\
\text { Landin } \\
\text { g } \\
\text { dengan } \\
\text { mengg } \\
\text { unakan } \\
\text { Joystic } \\
\text { k }\end{array}$ \\
\hline
\end{tabular}

Pembahasan kontrol AR.Drone 2.0 dengan WiFi berbasis LabVIEW.

Laptop pertama kali harus terhubung ke AR.Drone 2.0 via WiFi untuk mengontrol AR Drone 2.0. Ketika AR.Drone 2.0 dinyalakan, menciptakan titik akses WiFi lokal ad hoc 
yang dapat bergabung dari komputer. Pada jaringan ini AR.Drone 2.0 menentukan sendiri alamat IP statis dan membuka beberapa port standar untuk komunikasi. Gambar 2 menunjukkan saluran utama untuk komunikasi. Aliran video dan sensor data dikirim dari AR.Drone 2.0 ke komputer dan dengan bantuan joystick akan memberi perintah untuk mengontrol pergerakan AR.Drone 2.0. Semua komunikasi terjadi secara asynchronous

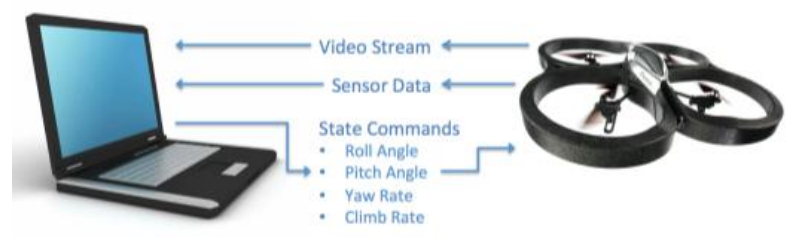

Gambar 3: Aliran komunikasi antara AR.Drone 2.0 dengan Komputer/Laptop

\section{KESIMPULAN}

Berdasarkan hasil penelitian tersebut, maka dapat disimpulkan sebagai berikut:

1. Telah dibuat sistem kontrol AR.Drone 2.0 dengan komunikasi $\mathrm{WiFi}$ berbasis LabVIEW.

2. Live streaming telah dapat ditampilkan dengan baik dengan gambar yang jelas, dimana aliran video dikirim oleh AR.Drone 2.0 pada port 5555 yang dapat digunakan untuk merekam kepadatan lalu lintas.

3. Informasi tentang drone ( status, posisi, kecepatan, kecepatan putaran mesin, dll) dapat ditampilkan dengan baik pada user interface.

4. Perintah kepada Drone untuk melakukan Take off, Hover dan Landing dapat ditampilkan dengan baik pada user interface.

\section{UCAPAN TERIMAKASIH}

Terima kasih saya ucapkan sebesarbesarnya kepada civitas akademika Universitas Pamulang dan ISTN serta keluarga.

\section{DAFTAR PUSTAKA}

Buku:

[1] Mogenson, Michael. The AR.Drone LabVIEW Toolkit: A Software Framework for the Control of Low-Cost Quadrotor
Aerial Robots. Medford: Tufts University, 2012.

[2] Piskorski, Stephane, Nicolas Brulez., Pierre Eline \& Frederic D'Haeyer. AR.Drone Developer Guide SDK 2.0. Parrot, 2012.

[3] Kilby, Terry\& Belinda Kilby. Make: Getting Started with Drones. San Fransisco: Maker Media, 2016.

[4] Travis, Jeffrey \& Jim Kring. LabVIEW for Everyone: Graphical Programming Made Easy and Fun, Third Edition. United States: Prentice Hall, 2016.

[5] Larsen, Ronald W. LabVIEW for Engineers. United States: Prentice Hall, 2011. 